\title{
STEPS centre
}

Lassa fever:The politics of an emerging disease and the scope for One Health

Annie Wilkinson
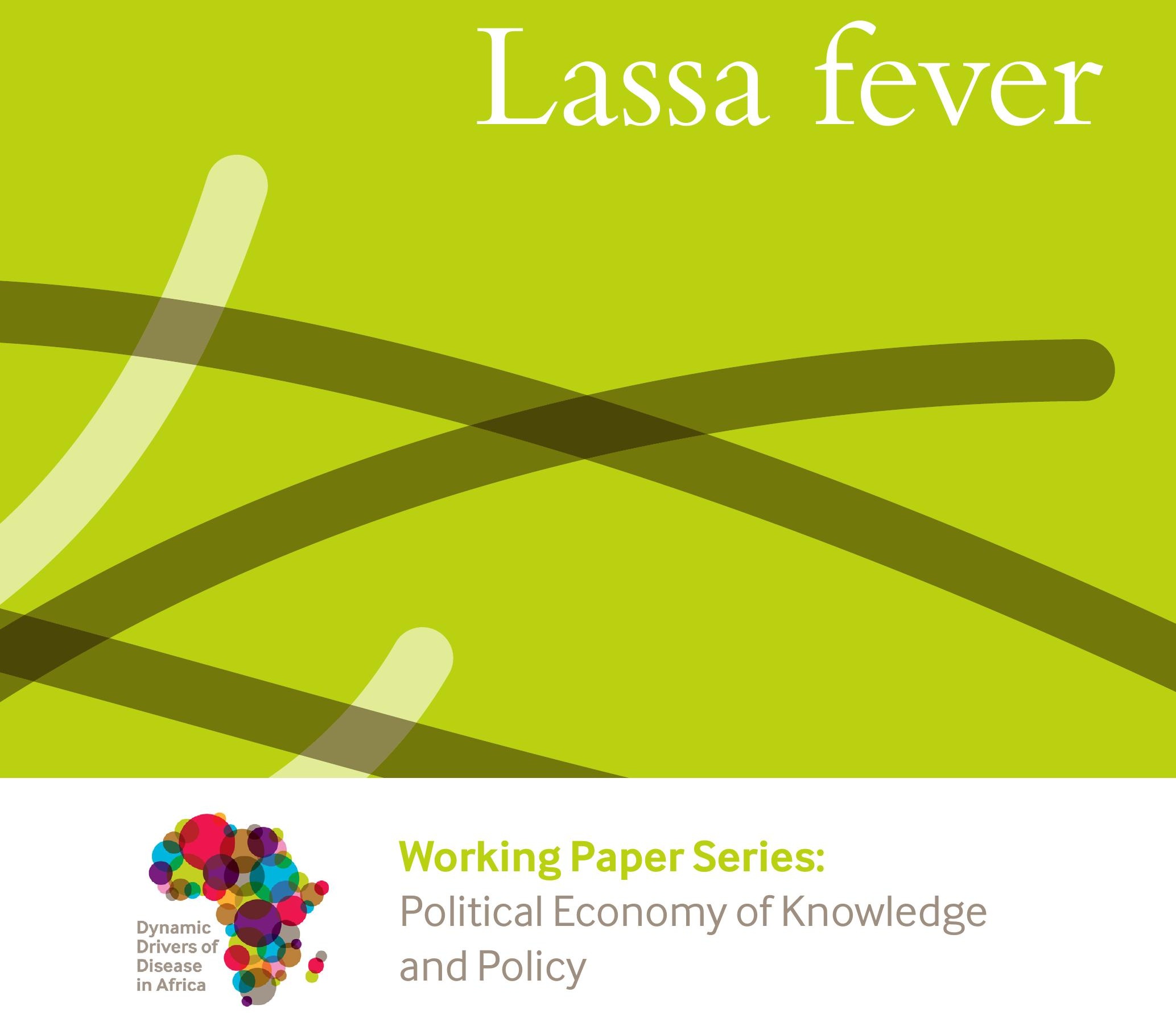

Working Paper Series:

Political Economy of Knowledge and Policy 


\section{Lassa fever: The politics of an emerging disease and the scope for One Health}

This paper explores the politics of knowledge and disease control for Lassa fever, a zoonotic viral haemorrhagic fever which is endemic in parts of West Africa. The Lassa virus has been classified as a 'Category A' pathogen, meaning it is considered to be one of the world's most dangerous organisms and a potential bioweapon. Unusually for a Category A pathogen it also causes endemic human disease with public health implications.

As a rodent-borne virus, Lassa fever is of interest to One Health. In this paper the interplay between security, public health and One Health perspectives are explored in Kenema, Sierra Leone, a long-term treatment and research hub. Running through policy processes are institutionalised responses to uncertainty which have privileged certain types of evidence leading to significant gains in laboratory and technology-based interventions. In securitisation debates, public health priorities are often judged to be undermined. However, this case shows that animal, human and environment interactions, and their socio-economic dynamics, have been marginalised on both national and international levels by political economies of knowledge and policy which tend to overlook the needs and perspectives of poor and rural populations.

\section{About the Author}

Annie Wilkinson is a postdoctoral researcher at the Institute of Development Studies, UK. Her work focuses on innovation and policy processes for zoonotic diseases and health systems.

\section{About the Dynamic Drivers of Disease in Africa Consortium}

The Dynamic Drivers of Disease in Africa Consortium is a multidisciplinary research programme designed to deliver muchneeded, cutting-edge science on the relationships between ecosystems, zoonoses, health and wellbeing with the objective of moving people out of poverty and promoting social justice. It is focusing on four emerging or re-emerging zoonotic diseases in four diverse African ecosystems - henipavirus infection in Ghana, Rift Valley fever in Kenya, Lassa fever in Sierra Leone, and trypanosomiasis in Zambia and Zimbabwe.

The Consortium (NERC project no. NE-J001570-1) is funded with support from the Ecosystem Services for Poverty Alleviation (ESPA) programme. The ESPA programme is funded by the Department for International Development (DFID), the Economic and Social Research Council (ESRC) and the Natural Environment Research Council (NERC).

\section{www.driversofdisease.org}

Follow us on Twitter QDDDAC_org

\section{About the STEPS Centre}

Today's world is experiencing rapid social, technological and environmental change, yet poverty and inequality are growing. Linking environmental sustainability with poverty reduction and social justice, and making science and technology work for the poor, have become central challenges of our times. The STEPS Centre (Social, Technological and Environmental Pathways to Sustainability) is an interdisciplinary global research and policy engagement hub that unites development studies with science and technology studies. We are developing a new approach to understanding and action on sustainability and development in an era of unprecedented dynamic change. Our pathways approach aims to link new theory with practical solutions that create better livelihoods, health and social justice for poor and marginalised people. The STEPS Centre is based at the Institute of Development Studies and SPRU Science and Technology Policy Research at the University of Sussex, with partners in Africa, Asia and Latin America. We are funded by the ESRC, the UK's largest funding agency for research and training relating to social and economic issues.

\section{www.steps-centre.org}

Follow us on Twitter Qastepscentre

For more STEPS Centre publications visit: www.steps-centre.org/publications

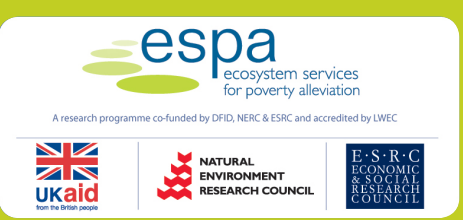

This is one of a series of Working Papers from the STEPS Centre www.steps-centre.org 
Lassa fever: The politics of an emerging disease and the scope for One Health

Annie Wilkinson

STEPS Working Paper 83 
Correct citation: Wilkinson, A. (2015) Lassa fever: The politics of an emerging disease and the scope for One Health, STEPS Working Paper 83, Brighton: STEPS Centre

First published in 2015

(C) STEPS 2015

Some rights reserved - see copyright license for details

ISBN: 978-1-78118-224-6

For further information please contact: STEPS Centre, University of Sussex, Brighton BN1 9RE

Tel: +44 (0) 1273915673; Email: steps-centre@ids.ac.uk; web: www.steps-centre.org

STEPS Centre publications are published under a Creative Commons Attribution - Non-Commercial - No Derivative Works 3.0 UK: England \& Wales Licence (http://creativecommons.org/licenses/by-ncnd/3.0/legalcode)

Attribution: You must attribute the work in the manner specified by the author or licensor.

Non-commercial: You may not use this work for commercial purposes.

No Derivative Works: You may not alter, transfer, or build on this work.

Users are welcome to copy, distribute, display, translate or perform this work without written permission subject to the conditions set out in the Creative Commons licence. For any reuse or distribution, you must make clear to others the licence terms of this work. If you use the work, we ask that you reference the STEPS Centre website (www.steps-centre.org) and send a copy of the work or a link to its use online to the following address for our archive: STEPS Centre, University of Sussex, Brighton BN1 9RE, UK (stepscentre@ids.ac.uk).

\section{c) creative}


Other STEPS Centre Working Paper titles in the Dynamic Drivers of Disease in Africa Consortium Political Economy of Knowledge and Policy Series:

One Health

Networks

Henipa

RVF

Trypanosomiasis

Tsetse
The political economy of One Health research and policy, Victor Galaz, Melissa Leach, Ian Scoones and Christian Stein

Towards One Health? Evolution of international collaboration networks on Nipah virus research from 1999-2011, Sophie Valeix

Responding to uncertainty: Bats and the construction of disease risk in Ghana, Linda Waldman, Audrey Gadzekpo and Hayley MacGregor

Rift Valley fever in Kenya: Policies to prepare and respond, Erik Millstone, Hannington Odame and Oscar Okumu

The politics of trypanosomiasis control in Africa, Ian Scoones

Politics of knowledge: whose knowledge matters in

trypanosomiasis policy making in Zambia, Catherine Grant 


\section{Contents}

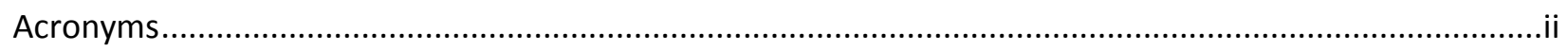

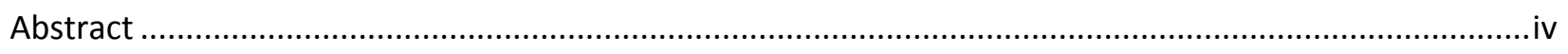

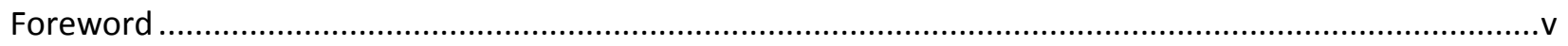

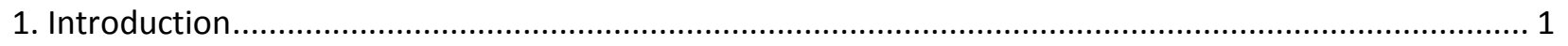

2. Policy processes and emerging diseases in practice .................................................................... 2

3. Calibrating 'a new virus disease of man from West Africa' .............................................................. 4

4. From neglected disease to priority pathogen ............................................................................ 7

5. Biodefense dollars: technology deficits and counter threats ....................................................... 10

6. Becoming a national public health problem: from unknown to known ......................................... 15

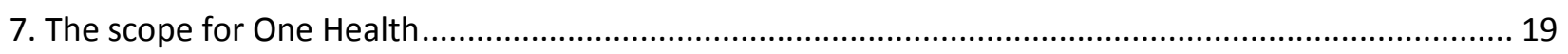

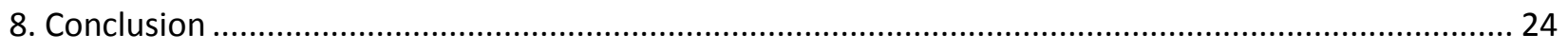

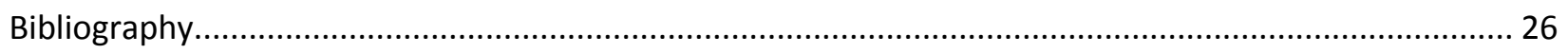




\section{Acronyms}

\begin{tabular}{|c|c|}
\hline AFRICOM & US Africa Command \\
\hline BSL-4 & BioSafety Level 4 \\
\hline CBEP & Cooperative Biological Engagement Program \\
\hline CDC & [US] Centers for Disease Control and Prevention \\
\hline DFID & [UK] Department for International Development \\
\hline DOD & [US] Department of Defense \\
\hline DTRA & [US] Defense Threat Reduction Agency \\
\hline ESHIA & Environmental, Social, and Health Impact Assessments \\
\hline EU & European Commission \\
\hline IDSR & Integrated Disease Surveillance and Response \\
\hline IHR & International Health Regulations \\
\hline $\mathrm{KGH}$ & Kenema Government Hospital \\
\hline LASV & Lassa virus \\
\hline MOHS & Ministry of Health and Sanitation \\
\hline MRU-LFN & Mano River Union Lassa Fever Network \\
\hline NGO & Non-Governmental Organisation \\
\hline NIAID & [US] National Institutes of Allergy and Infectious Diseases \\
\hline NIH & [US] National Institute of Health \\
\hline OFDA & Office of United States Foreign Disaster Assistance \\
\hline PHU & Peripheral health unit \\
\hline PPE & Personal protective equipment \\
\hline SARS & Severe acute respiratory system \\
\hline SLIEPA & Sierra Leone Investment and Export Promotion Agency \\
\hline
\end{tabular}


UN

USAID

VHF

VHFC

WHO
United Nations

United States Agency for International Development

Viral Haemorrhagic Fever

Viral Haemorrhagic Fever Consortium

World Health Organization 


\begin{abstract}
This paper is about the politics of knowledge and disease control for Lassa fever, a zoonotic viral haemorrhagic fever which is endemic in parts of West Africa. Implications extend beyond West Africa as Lassa virus has been classified as a 'Category A' pathogen, meaning it is considered to be one of the world's most dangerous organisms and a potential bioweapon. Unusually for a Category A pathogen it also causes endemic human disease with public health implications. As a rodent borne virus, Lassa fever is of particular interest from a One Health perspective. The interplay between security, public health and One Health approaches are explored through ethnographic and interview based research in Kenema, Sierra Leone, a long-term treatment and research hub. 'Biodefence dollars' have provided the majority of recent funding in Sierra Leone and have created opportunities for both local and international actors to address a neglected disease. Yet the increased resources have been limited in important ways, highlighting gaps between national public health needs and the implications of expanding biosecurity applications in global health and development. Running through policy processes are institutionalised responses to uncertainty which privilege certain types of evidence, leading to an emphasis on laboratory and technology based interventions. In securitisation debates, public health priorities are often judged to be undermined. However, this case shows that attention to animal, human and environment interactions and their socioeconomic dynamics has been negligible. Lessons from Lassa and the Ebola crisis suggest that a new approach to managing human, animal and ecosystem health, which draws in a range of expertise, which recognises and addresses socio-economic drivers and differential vulnerabilities, and which engages with the priorities of local populations should be a priority.
\end{abstract}




\section{Foreword}

In Sierra Leone, the focus of this paper, the 'Lassa ward' and 'Lassa lab' at Kenema Government Hospital $(\mathrm{KGH})$ became the frontline of the country's Ebola epidemic when the disease first entered the country. Many of the Lassa ward and laboratory staff died. The loss of these knowledgeable and committed staff is a tragedy and a travesty. This paper is dedicated to them, in particular to Mbalu Fonnie, Vandi Sinnah, Alex Moigboi, Alice Kovoma, Dr Sheik Humar Khan and Mohammed Fullah. Though far from a fitting tribute, the research on which it is based was only possible with their support and patience.

The bulk of this text was drafted before Ebola took hold in West Africa, as a case study focusing on the political economy of research, policy and disease control for Lassa fever. The subsequent disaster has made this task even more urgent. As of January 2015 attention is still fixed on Ebola, however the story of the Mano River's temporarily forgotten 'other' viral haemorrhagic fever provides some insight into the foundations of the catastrophe. 


\section{Introduction}

Before Ebola ravaged Guinea, Liberia and Sierra Leone in 2014, the combination of persistent fever, muscular pain, nausea, diarrhoea and red eyes signalled a different but similarly feared disease: Lassa fever, a rodent-borne viral haemorrhagic fever (VHF) which can infect humans with devastating effect. Indeed Lassa was initially suspected as the cause of the mysterious fever that sickened residents of Guinea's forest region, now known to have been Ebola. Since the discovery of Lassa fever in 1969, only Sierra Leone, Liberia, Guinea and Nigeria have recorded regular cases, with regions in each country considered endemic. Lassa fever was long thought to be confined, mysteriously, to these few hotspots in West Africa and consequently they are where most disease control efforts have been concentrated. Recently however, Lassa fever's home territory appears to be growing with cases identified in Ghana and previously non-endemic areas of Sierra Leone and Nigeria (Sogoba et al. 2012; Gire et al. 2012). At the end of 2014 an outbreak occurred in Benin, killing nine people. The apparent expansion of Lassa and the detection of Ebola in the Mano River Union has revealed new dimensions to the region's viral make up. In light of these developments, it is timely to consider the scope of past, present and future disease control efforts and the science-policy politics which shape them.

The trajectory of Lassa fever in Sierra Leone is striking. In a decade it has transitioned from being a neglected, albeit renowned, tropical disease into a high priority pathogen of international importance which attracts considerable research funding. In $2007^{1}$ the dilapidated 'Lassa ward' at KGH, the longest running treatment facility dedicated to the disease in West Africa, was joined by the 'Lassa lab'. The combined facilities serve as a field site for international research collaborations on Lassa and other viral haemorrhagic fevers. The headline story is that most of this new funding is from biodefense coffers, a fact which has not gone unnoticed. The laboratory in Kenema has been called a 'US anti-terror outpost' (Akam 2011). A rumour circulating in Sierra Leone during the Ebola epidemic was that Ebola, or some mutant Lassa-Ebola hybrid, had been created and released from the laboratory, either deliberately or as biowarfare gone wrong. While these claims are far from the truth, the way global biosecurity concerns have affected efforts to control Lassa in this part of the world is a point of concern. It is unusual, and perhaps unique, that an Ebola outbreak occurred in a setting where viral haemorrhagic fevers were already being studied and treated routinely, inviting the question of why Sierra Leone was not better prepared. Lassa then, adds some much needed context, shining a light on some poorly understood dimensions of science policy processes and global health in practice. In particular the interactions between international biosecurity agendas and national public health efforts, their scales and priorities, and the forms of preparedness they have engendered, or not as the case may be. It then considers another perspective, that of One Health. One Health emphasises how animal, human and ecosystem health are interdependent and how in the face of complex and uncertain change they cannot be secured separately (Zinsstag et al., 2011). As a zoonotic disease, understanding the relationship between animal, human and disease ecosystems offers considerable potential for disease control policy.

\footnotetext{
${ }^{1}$ Work had begun in 2005 but the first routine tests were available in 2007.
} 


\section{Policy processes and emerging diseases in practice}

Although Western alarm about newly emerging diseases was always relevant to Lassa fever (See Fuller 1974; Garrett 1994), post 9/11, and the US anthrax attacks, it took on a new life. Lassa virus was assessed for its possible use as a bioterrorist agent (Borio et al. 2002) and is now categorised by the US Centers for Disease Control and Prevention (CDC) and US National Institutes of Allergy and Infectious Diseases (NIAID) as a Category A agent (NIAID 2012; CDC 2012). ${ }^{2}$ Category A is the highest risk level of 'select agents' with potential for use in bioterrorism on account of their ability to spread easily and to cause major public health impacts, including high mortality. In parallel to fears of weaponisation, outbreaks of avian flu and SARS had raised anxiety about pandemics, putting pressure on global health agencies to bolster alert and response frameworks. Lassa fever was included as a notifiable disease under the World Health Organization's (WHO) revised International Health Regulations (IHR) due to its epidemic prone nature and potential to cause economic and social disruption (WHO 2005a; WHO and CDC 2010). The heightened concern and control surrounding Lassa fever illustrates the phenomena of securitisation whereby issues are (re)interpreted as existential threats (Elbe 2010: 478), a trend increasingly common in a geopolitical landscape preoccupied by globalisation and security (Ingram 2005). For many, the Ebola outbreak will have justified such concerns. The social, health, economic and educational systems of Sierra Leone and Liberia were brought as close to the brink of collapse as they have been at any time since their civil wars. It is all the more important to understand how such cross border interpretations of risk and systems for managing them connect with disease control realities in local contexts.

Beneath the swirl of these security anxieties is an interesting predicament. Lassa fever is the only Category A pathogen which also causes regular human disease and as such constitutes a significant public health challenge. In securitisation debates, biosecurity priorities are often portrayed as being in opposition to those of public health (Lakoff and Collier 2013; Elbe 2010). Two basic points are made about framing health problems as security issues: on one hand, it successfully raises awareness and mobilises resources, but on the other these resources can be severely limited and privilege defence priorities instead of civilian populations. Scholars have highlighted how different values, assumptions and knowledge making processes cause problems to be framed in distinct ways (Jasanoff 2005; Schön and Rein 1994). Policy narratives, convincing storylines based on these framings, are mobilised by networks of actors to promote specific courses of action (Roe 1994). Diverse narratives, and their varying impact, tend to reflect the interests, institutional contexts and power of actor networks (Leach et al. 2010a; Keeley and Scoones 2003). More powerful actors and networks can promote dominant narratives and perspectives, suppressing those of the less powerful. These insights put political and institutional power dynamics at the centre of investigating how biosecurity and public health concerns play out in a 'weak' health system context, and in assessing the prospects of an integrated and interdisciplinary approach to human and animal health.

Patricia Wald has identified an 'outbreak narrative' to be part of popular discourse on emerging diseases, especially in TV, film and media (Wald 2008). The arc of an outbreak narrative highlights the sudden

2 Category $A$ is the highest risk level in the CDC's classification of 'select agents' with potential use in bioterrorism on account of their ability to spread easily and to cause major public health impacts, including high mortality. Other Category A agents are: Anthrax, Botulism, Plague, Smallpox, Tularemia, and Viral Haemorrhagic Fevers, which includes Lassa Fever, along with others like Ebola, Marburg and Machupo. 
emergence of a new disease (often in African-type landscapes), the potential for mass-spread, especially across international borders, and the critical role of epidemiological science in tracking and containing the disease. The dominance of the outbreak narrative in policy approaches devised by international agencies and Northern governments for epidemic disease has been pointed out (Leach et al. 2010b). Such views from above can be contrasted with alternative and ground level perspectives on disease. Within Sierra Leone there is a local version of the exceptional status that the disease occupies on the international stage. It has, as one survivor put it, a 'big name'. Lassa, it was said, at least before Ebola, is worse than HIV because it kills so quickly. Much is made of the gory symptoms involved in a case of 'classic Lassa': red eyes, extreme fever and bleeding. A photo on the wall of the Mano River Union Lassa Fever Network (MRULFN) field office in Kenema showed a taunting slogan painted on the back of a taxi which read in Krio, 'we de gie dem Lassa fever' (we'll give them Lassa fever). Rural and urban residents alike will tell you that Lassa is carried by rats, or arata in the local Krio language, and that catching, playing with or eating them is to be avoided. Fear of Lassa fever is fuelled by the scores of health workers who have died in nosocomial infections. Yet, despite its big name, Lassa fever is characterised by ambiguity and multiplicity. For all the well-known assertions about classic Lassa, it is not clear what a typical case looks like, or how best to diagnose and treat it (though new diagnostics have improved this dramatically). Not only is knowledge of the virus's geographical distribution patchy but it is not clear who is most vulnerable, when and why. The elusive 'solid evidence base' is blamed, by scientists, on the limitations of research tools (particularly diagnostics) and regional conflicts which made research near impossible for a decade (Khan et al. 2008). As an emerging disease, uncertainly surrounds Lassa but close inspection suggests the issue is more than a patchy evidence base. The way different actors have interpreted and dealt with this incomplete knowledge is fundamental to the unfolding policy processes.

Of interest here, then, is not only the narratives, but the socio-technical processes and contexts through which they emerge. It is notable that in Sierra Leone, since the war at least, most of the activity on Lassa is conducted out of one site, with highly interlinked actor networks consisting of a small group of national medical, clinical and outreach staff and a limited number of international research organisations. The distinct actor networks and opposing institutional paradigms described in other policy analyses are missing. Collier and Ong's (2005) concept of 'global assemblages' which they use to describe the configurations of people, artefacts, brokers, economies, and more, through which global forms (such as biosecurity) are brought to life in particular settings is apt. As a lens this emphasises the manipulation and (re)construction of distant policy frameworks in line with local contexts. Presented here is a brief history of how narratives around the disease and the KGH site have shifted, reflecting different assemblages of technology, values, priorities and approaches to knowledge.

While the discovery and early characterisation of Lassa fever has been recorded in a number of books (Fuller 1974; McCormick et al. 1999; Garrett 1994) later periods of research are less well recorded. Research reported here is based on fieldwork carried out between 2009 and 2013 around KGH, Eastern Sierra Leone. Observational data was supplemented by documentary reviews and interviews with core actors who were involved in policy making, surveillance, research and providing medical care in the country. Interviews were conducted with experts at the WHO, universities, biotech companies and the CDC. In addition, the views of non-core actors (e.g. people working in agriculture or mining industries, or related government departments) were sought to identify contrasts between expert scientific discourses and those of the public, and to explore One Health concepts with those working in relevant non-medical sectors. 


\section{Calibrating 'a new virus disease of man from West Africa'}

A look back at the early days of Lassa fever research and control sees two trajectories emerge. In one, the apparent danger of the virus compels the use of increasingly institutionalised norms and practices for biosecurity. As a result, knowledge production for Lassa fever becomes associated with, and more restricted to, highly controlled environments and to the settings where achieving such control is feasible. In the other, the complexities of the disease and the Mano River region evade control and security. Research on the intricacies of disease-environment interactions on the ground proved difficult to sustain. This opened up gaps between the formal generation of scientific research evidence, which for rigour and safety was increasingly done in non-natural settings (see Knorr Cetina (1999) for a discussion of 'laboratization'), and local management and experiential knowledge of the disease in context.

Lassa fever was first identified in the town of Lassa, Nigeria, in 1969. It is described in early scientific reports as a 'new virus disease of man from West Africa' (Frame et al. 1970). John Fuller (1974) recounts how Dr John Frame at Columbia University was intrigued by records of unexplained fevers in Africa and arranged for samples from such cases to be sent to him in the US. Lassa fever emerged through this route, after two missionary nurses in the Nigerian town of Lassa died of a dramatic fever, a third nurse, Penny Pinneo, was evacuated to the US suffering from similar symptoms. When Penny's plane arrived, Dr Frame was waiting at the airport to take a blood sample. Biosafety procedures for dealing with the new virus were minimal. Penny was flown from Nigeria to the US on a routine Pan Am flight, samples were transported freely and much of the initial investigation into the virus was done at Yale Arbovirus Research Unit which was not a high security facility by today's standards. During that early research there were two laboratory based infections in the US, a laboratory technician at the Yale Arbovirus Research Unit died and a senior researcher contracted Lassa fever but survived. In light of these events ad hoc protective procedures were applied (Fuller 1974), ${ }^{3}$ laying the ground for the regulatory regime which has shaped the production of research and knowledge about the disease since.

After the fatal and near-fatal cases at the Yale laboratory all research on live Lassa virus was moved to the 'hot lab, the CDC's high containment facility (Fuller 1974). Since then informal biosafety arrangements have matured into formal regulations and standards with pathogens classified according to their perceived risk. Lassa virus has been classified as a biosafety level 4 (BSL-4) pathogen and requires the highest possible containment facilities. A side effect of tighter regulation was that research into the virus became more specialised and resource intensive. BSL-4 laboratories are hugely expensive to maintain, and therefore research on Lassa virus was restricted. In 2007 there were only 20 BSL-4 laboratories in the world (Gronvall et al. 2007) and when research on Lassa began there were even fewer. None of these were, or are, in West Africa. The ratcheting up of biosecurity reflects an international health regime increasingly concerned with risk aversion but which, inevitably, left some places behind. The conditions which were now considered necessary to be safe to carry out research on Lassa virus were, and are, not easily met in West African settings where gloves could not be counted on, let alone full personal protective equipment (PPE), water and electricity. In Sierra Leone the Lassa ward had to operate at a more pared-down approach to biosecurity, something which just about worked for Lassa fever but did not for Ebola. The gulf between the biosafety measures which materialised in specialised facilities outside of Africa and what was possible in Mano River health facilities can be seen as evidence of 'structural violence' (Farmer 1999; Farmer et al.

\footnotetext{
${ }^{3}$ For example, staff with young children were not allowed to work on the investigations (See also Fuller 1974: 142).
} 
2004). This manifestation of extreme inequality can turn hospitals into disease vectors and leave health care workers continually vulnerable to infectious diseases for lack of the most basic resources.

In West Africa in the late 60s and early 70s, away from the 'hot labs', Lassa fever continued to raise its head which allowed field investigations to get underway. In 1972 the rodent host, Mastomys natalensis, was identified after outbreaks in the towns of Tongo and Panguma in Eastern Sierra Leone (Monath et al. 1974). These settlements and the area surrounding them have been known as the Lassa belt ever since, and are considered to have some of the highest Lassa incidence rates in West Africa. After the 1972 outbreaks in Sierra Leone, the CDC set up research stations in Segbwema, Kenema and Panguma. The main treatment programme was based in Segbwema at the Nixon Memorial Mission Hospital and run by $\mathrm{Dr}$ Aniru Conteh (Bausch et al. 2004; McCormick et al. 1999). During this time the CDC conducted studies on a range of topics including the pathogenesis of Lassa fever, prevalence, clinical management, and on risk factors and their mitigation (Monath 1975; Monath et al. 1974; Monath et al. 1973; McCormick et al. 1999; McCormick et al. 1987a; McCormick et al. 1986; McCormick et al. 1987b; Price et al. 1988). Rodent to human transmission routes, either direct (consumption of rodents) or indirect (contact with food, water or objects contaminated by rodent body fluid), were characteristic. Based on these basic understandings of transmission, efforts to sensitise communities to Lassa fever with radio jingles and outreach activities began and have continued almost unchanged ever since. In 1991, due to the outbreak of war which spilled over the Liberian border not far from Segbwema, Lassa activities moved to KGH, where they remain despite KGH being outside of the hyper-endemic Lassa belt. Civil instability caused the CDC to close their programmes and pull out of Sierra Leone entirely in 1993. They moved some of their work to Guinea but the incidence of Lassa was lower there and the Organisation's interests were soon diverted (Tulane researcher: Kenema, 27 March 2010). By 2003 the Guinea programme was also closed.

After the departure of the CDC from Sierra Leone the Lassa ward was left largely without support. It was kept going with the guidance and commitment of Dr Conteh. In 1996, in the wake of a steep rise in Lassa cases, and with the country still blighted by war, the British medical relief organisation, Merlin, took the reins in Kenema by providing health promotion and treatment activities but not laboratory support (Khan et al. 2008). Merlin attempted to strengthen the Ministry of Health and Sanitation's (MOHS) capacity to deal with Lassa by developing case identification and treatment protocols, conducting Knowledge, Attitude and Practice surveys (Richmond and Baglole 2003) and doing sensitisation and training with communities and healthcare workers (Merlin 2002). Merlin also raised funds for a laboratory but this was not completed (CDC staff: Skype, 29 October 2013).

On one level, the trajectory of Lassa fever's emergence - the first cases in Nigeria, the US infections and subsequent outbreaks in Africa - provided the key events for a typical 'outbreak narrative' (Wald, 2008). On the international stage Lassa fever was an emerging disease which could follow this logic of outbreak and containment, with CDC field stations doing pivotal work to understand and control the disease. Books such as 'Fever: the hunt for the new killer virus' (Fuller 1974) and 'Level 4 - Virus Hunters of the CDC' (McCormick et al. 1999) reflect such storylines. The ongoing problem of Lassa fever in Sierra Leone proved trickier to narrate and manage. Lassa fever disease control was dependent on international whims and humanitarian assistance, made worse by the regional conflict. By the end of the war, Lassa was proving itself to be a serious public health concern, yet the steady stream of cases was not matched by resources. It was described as an, 'unheralded problem' (Birmingham and Kenyon 2001), and the, 'poster child of 
neglected diseases' (Donaldson 2009). ${ }^{4}$ These claims reflect a shift in perspective on Lassa, it could no longer simply be conceived of as an exotic new disease to hunt down but was now an endemic disease caught in the politics of under-resourced health systems.

${ }^{4}$ Donaldson's (2009) book, and this quote, is based on experiences prior to the formation of the MRU-LFN. 


\section{From neglected disease to priority pathogen}

The confluence of the outbreak narrative with a range of security concerns at local and international levels meant that Lassa was not destined to remain a typical neglected disease. The year 2004 was a devastating one for Kenema, but one which marked the beginning of a new phase. With stability returned to Sierra Leone, Merlin, who were primarily an emergency relief organisation with no mandate to provide longterm support, were looking to leave (Tulane researcher: Kenema, 27 March 2010). The virus, however, was wreaking havoc with seemingly renewed vigour. A nosocomial outbreak linked to KGH's paediatric ward saw 95 paediatric cases admitted to the Lassa ward between 1 January and 24 April 2004 (WHO 2005b). There were also cases among expatriates and peacekeepers which drew additional attention to the illness. With the ward overflowing, a further blow was the death of Dr Conteh after he contracted Lassa fever through a needle stick injury.

The Office of United States Foreign Disaster Assistance (OFDA), part of the US Agency for International Development (USAID), set up a task force to deal with Lassa fever. They brought stakeholders from Sierra Leone, Guinea, Liberia, WHO, European Commission (EU), and other Non-Governmental Organisations (NGOs) together to develop a regional strategy. OFDA gave a small amount of funding to the WHO to coordinate this and to set up a laboratory in Kenema. So, in 2004, the Mano River Union Lassa Fever Network (MRU-LFN) was formed to strengthen scientific cooperation, patient management, surveillance, laboratory capacity and information communication and education (MRU-LFN 2004). A former CDC staff scientist, on secondment to the WHO at the time, recalled that regret over the death of Dr Conteh was a 'tipping point' in setting up the MRU-LFN. Previous WHO missions to Sierra Leone had come to little and there was a sense that Dr Conteh had been, 'left in the lurch, without any help,' and they wanted to put this right to ensure that it would not happen again (CDC staff: Skype, 29 October 2013). WHO site visits confirmed a dire situation in Kenema. Foundations for a Lassa laboratory had been laid but had been poorly constructed and left unfinished. The main hospital laboratory had minimal capacity. Tales of stigma in the community involved accusations of witchcraft and houses of Lassa victims being burnt. The Lassa ward was perceived as somewhere people went to die; that once patients went in they would not come back. There were (and still are in some places) rumours that patients were given fatal injections to stop the disease from spreading. Much of this has been echoed, and amplified, with Ebola.

Central to the WHO/OFDA plan was the idea of building a laboratory on the site Merlin had identified. The laboratory was intended as a 'research campus' where international researchers would pay to use the facilities. The hope was that the laboratory could sustain itself with this research funding and provide support to the ward and to the general hospital and laboratory (CDC staff: Skype, 29 October 2013). The Kenema laboratory was to be connected to laboratories in Guinea and Liberia through the MRU-LFN, with Governments cooperating on surveillance (MRU-LFN 2004). There were also plans for a new isolation ward at KGH for which the EU had committed funds (WHO 2005b). While programmes in Liberia and Guinea either never materialised or could not be maintained, a laboratory was established in Kenema, where it continues to run nearly ten years later.

The events of 2004 took place in a global health landscape which was increasingly security conscious. Therefore, from the start, it was entwined with a collection of biosecurity concerns. As one long-term researcher recalled: 
In 2004 a lot of things were happening simultaneously. There was epidemic spread in the Sierra Leonean population. There were cases in UN peacekeepers. There were cases in relief workers. There was a Red Cross surgeon who got Lassa and died. In the United States side of things people were of course worried about Lassa as a Bioterrorist agent. And then kind of culminating with Aniru Conteh, who ran the Lassa ward, getting Lassa and dying.

(Tulane researcher: Kenema 27 March 2010)

During the MRU-LFN inception phase further security anxieties emerged. After the war, with the influx of aid workers and peacekeepers, Lassa was painted as a threat to post-conflict redevelopment. A Weekly Epidemiological Record from the WHO, which played a key role in setting up the MRU-LFN, spelled this out:

Civil unrest in the Mano River Union region created newly vulnerable populations, including refugees and humanitarian relief workers. There have been several recent fatal cases of Lassa fever among United Nations peacekeeping forces. The return of areas to government control and the rebuilding of civil society in Liberia and Sierra Leone puts aid workers at risk of contracting Lassa fever.

(WHO 2005b)

The framing of Lassa fever as a threat to the fragile new peace by the risks it posed to the personnel involved in ensuring that peace, would have made a powerful statement in a country emerging from a decade of war. Indeed, the doctor employed to replace Dr Conteh in running the Lassa ward recalled senior staff in the MOHS persuading him to take up the post by warning him that 'the peacekeepers will leave if they don't have a doctor (KGH and Lassa ward clinician 1: Kenema, 23 October 2013).

The creation of the MRU-LFN also saw Lassa fever control dovetail with regional post conflict diplomacy. As countries where Lassa fever was endemic, Sierra Leone, Liberia and Guinea, also made up the Mano River Union economic sub-region, ${ }^{5}$ staff from WHO saw an opportunity to use that entity to get leverage for Lassa fever work. High level ministry staff from each Mano River Government were invited to participate in developing the five year MRU-LFN strategy. The hope was that tackling the mutual problem of Lassa would foster and capitalise on inter-country cooperation in a historically volatile region. However, as the WHO staff coordinating this reflected, there was relatively little input and engagement from the three Governments which, in hindsight, was not enough to realise the network's broader aims (CDC staff: Skype, 29 October 2013).

Efforts to establish regional cooperation and surveillance should be viewed as part of wider efforts to strengthen surveillance for global health security post Severe acute respiratory system (SARS), and in the wake of outbreaks of avian flu in the early 2000s WHO revised the IHRs and established structures like the Global Alert and Response Network to ensure global public health security (Dry 2008) through surveillance and early warning systems. The MOHS adopted the WHO's Integrated Disease Surveillance and Response ${ }^{6}$

5 Ivory Coast joined in 2008.

6 IDSR was developed by WHO African Region as a cross-cutting way of health system strengthening and global surveillance. 
(IDSR) in order to implement the IHRs, under which Lassa fever was included with other 'priority communicable diseases' (MOHS 2008: 3-4).

In what now appears a prophetic view, senior staff at the MOHS Disease Prevention and Control Directorate articulated a complementary vision of disease surveillance which encompassed lives saved and the protection of economic and public order both within and across borders:

The concern is to save lives. If you contain the situation locally then the tendency is to save lives, it doesn't go beyond your borders, it doesn't restrict the labour market, the global travel. If you let the situation go beyond then it will disrupt travel and trade. It is good for all of us to stop that. (Senior MOHS official, Disease Prevention and Control Directorate: Freetown, 28 April 2011)

These governance tools worked on the principles of detection and containment at source, but they have been criticised for prioritising the safety and interests of Northern populations (Elbe 2010; Dry 2008; Calain 2007) while overlooking the social and material circumstances which produce disease in specific contexts (Hinchliffe 2014). A more immediate concern, revealed dramatically by Ebola but evident with Lassa earlier, is whether low resource governments and health systems really have the capacity to implement the IHRs (Gostin and Friedman 2014).

The establishment of the MRU-LFN did a great deal to improve the situation in Sierra Leone, as described in the next section, diagnostics have been available routinely to suspect Lassa cases in Kenema since 2006. Yet, outside of laboratory diagnostics, progress on the MRU-LFN's objectives of surveillance, case management, and education have been more limited. The fact that the laboratory was even built was down to the 'sheer will of a few' rather than effective stakeholder cooperation (CDC staff: Skype, 29 October 2013). Many of the original commitments made by the MOHS and NGOs were not fulfilled. The laboratory was finished in the end with the help of Pakistani peacekeepers who were stationed near Kenema and who offered their help after some of their troops contracted Lassa fever. They donated supplies and arranged for the biosafety cabinets which could not be taken over the dirt roads from Freetown to be airlifted in the UN helicopter to Kenema.

Both past and present WHO staff describe difficulties in getting original stakeholders, including the MOHS, to stick to their commitments (WHO representative: Geneva, 14 December 2012 and CDC staff: Skype, 29 October 2013). The foundations of the new EU funded ward were laid but never completed as match funding did not materialise. Eventually the WHO, both Country Office and Geneva staff, pulled back. The WHO country representative was moved to another position, the Geneva based staff were sent back from time to time but, as a former staff member recalled, 'somewhere down the line when the glow of the outbreak was done', attention was turned away from Lassa (CDC staff: Skype, 29 October 2013).

The security rhetoric on peacebuilding and regional cooperation was enough to bring in some initial resources, but it was not enough to maintain the commitment of the original stakeholders. Although Liberia send samples to Kenema for retrospective diagnosis there has not been significant cooperation between Mano River Countries on the issue of Lassa fever otherwise (Senior MRU representative, Freetown, 06/02/13). The lack of regional laboratory capacity and cross border networks for surveillance has been a factor in the struggle to control Ebola. 


\section{Biodefense dollars: technology deficits and counter threats}

Of the various security 'problems' attached to Lassa the one which has raised the most resources, and eyebrows, is biodefense, specifically that which is tied to US biodefense interests. While the headlines may refer to bioterrorism (see Akam 2011) on closer inspection the biodefense assemblage reflects a diverse range of problems and interests on the ground. Nevertheless, the scope of research activities have been heavily geared towards human health and, in particular, the development of technologies to mitigate disease in humans. Substantial progress has been made on these admirable aims. In contrast, comparatively less progress has been made in improving prevention or understanding human-animalenvironment interactions.

When the MRU-LFN was set up diagnostics were identified as a priority. Cumbersome and expensive to produce, routine serological tests were unavailable in West Africa (Tulane researcher: Kenema, 27 March 2010 and Tulane laboratory scientist: Kenema, 2 March 2010). Recognition of this critical technologydeficit brought biotech actors more centrally into Sierra Leone's Lassa fever world, marking a gear change from the activities carried out by humanitarian and international agencies up to that point. In parallel, the classification of the Lassa virus as a Category A pathogen created funding incentives and possibilities for researchers and biotech companies to work on otherwise neglected diseases. That classification frames Lassa fever as a threat to US national security which necessitates, 'special action for public health preparedness' (CDC 2012). Significantly, the greater part of the billions of dollars which have been raised and spent on biodefense by the US Government since 2001 have both biodefense applications and nonbiodefense applications, for instance in health care, public health or other security applications (Schuler 2004; Schuler 2005; Franco 2009). In the case of Lassa fever, research is described as strengthening US medical capacity to deal with an attack or outbreak as well as helping to deal with the ongoing public health situation in Sierra Leone. The project summary of Tulane's successfully funded proposal to the United States' National Institute of Health $(\mathrm{NIH})$ to develop diagnostics for Lassa fever exemplifies this:

This project will develop Diagnostics For Biodefense against Lassa fever, a severe, often fatal viral haemorrhagic fever (VHF). Because of its high case fatality rate, ability to spread easily by humanhuman contact, and potential for aerosol release, Lassa virus (LASV), the causative agent of Lassa fever, is classified as a Biosafety Level 4 and NIAID Biodefense Category A agent. The potential use of LASV as a biological weapon directed against civilian or military targets necessitates development of, 'effective, rapid, highly sensitive, specific, easy to use, adaptable, and costeffective medical diagnostics for public health laboratories, hospital-based clinical laboratories, and point-of-care use (RFA-Al-08-001)' to diagnose individuals exposed to and/or infected with LASV. The impact of Lassa fever in endemic areas of West Africa is immense, and a safe and effective diagnostic can also provide a very significant public health benefit.

(Garry 2004: 64)

This was one of the first and largest grants using the new Lassa lab in Kenema for field research. With a budget of approximately US\$ 9-10million, it exemplifies the dual justification of this kind of research. Another five year grant, which focuses on the role of humoral immunity in the protection or pathogenesis of Lassa fever, which has implications for developing effective treatment, was awarded from NIH's biodefense allocations in 2009/10 for US\$15million (Homeland Security Newswire 2010). The portfolio of biodefense related projects in Kenema also includes those of Metabiota, a private for-profit company. Metabiota had at least three grants from the Defense Threat Reduction Agency (DTRA) and Cooperative 
Biological Engagement Program (CBEP), both of which are US Department of Defense (DOD) agencies. Metabiota's work initially concentrated primarily on the pathogenesis of Lassa fever, with applications for treatments and vaccines. More recently they have carried out modelling research to understand the cycle of transmission in relation to climate (Metabiota staff: Skype, 3 October 2013). To put these grants into perspective, the Sierra Leonean MOHS was allocated approximately USD\$19,562, 598 in 2009 to run the national health system. The significance of these well-funded research projects to a small site in Eastern Sierra Leone is considerable.

In 2010 the Viral Haemorrhagic Fever Consortium (VHFC) was established. The Consortium brings together researchers working on Lassa fever, including Tulane, Scripps Research Institute, Broad Institute, Harvard University, University of California at San Diego, University of Texas Medical Branch, Autoimmune Technologies LLC, Corgenix Medical Corporation, KGH and Irrua Specialist Teaching Hospital in Nigeria. The driving force behind this consortium is to understand mechanisms related to the human immune response to Lassa virus infection. ${ }^{8}$ Collectively, the general approach has been to do research orientated towards the development of products, such as diagnostics, drugs or vaccines. A senior scientist at one of the Consortium's biotech firms summarised it in an interview. You're never going to eradicate the virus,' he said, 'what we want to do for the next ten years is just get into a system where we can diagnose them quickly, treat them quickly and reduce the mortality rate' (Wallace 2011). Another strand of work in the Consortium is the genomic studies of the virus and exposed humans being led by researchers at Harvard University. The researchers were prompted to pursue this work when they found a gene under positive natural selection in the Yoruba of Nigeria which appeared to be related to Lassa virus infection. This research centres on discovering what viral and host genetic factors influence suceptibility and resistence to infection and disease. The hope is that understanding these genetic factors may help in the development of effective treatments and interventions (Harvard University researcher: Skype, 4 October 2013).

The substantial funding won by members of the VHFC and Metabiota is a result of Lassa's framing as a US national security threat. The narrative, spelled out in the Tulane University led 'Diagnostics for Biodefense' grant application, is that deliberate or accidental release of Lassa virus on unprotected US citizens or troops could be a major public health incident. The public health issue in West Africa is mentioned in the grant application but only after the security point has been made. One Tulane researcher explained:

If you fell into the Category A, that's where the big money was. OK so if you wanted to do big money research you had to come up with some really good ideas, whether it was diagnostics, or vaccines or therapeutics [...] if you picked a Category A agent your chances of being funded probably went up significantly.

(Tulane researcher: Kenema, 2 March 10)

In picking diagnostics, vaccines or therapeutics the focus of work in Sierra Leone followed a pattern in biodefense research towards the development of medical countermeasures (Vogel 2008). Vogel argues that the US approach to biodefense has been captured by a 'science based approach' which emphasises the development of biotechnology, tech fixes, as the most effective way to deal with uncertain threats

7 The exchange rate in 2009 was US\$1 = 0.00033 SLL. Original total in Sierra Leone Leone's (SLL) was $59,280,600,000$. Figures taken from Save the Children UK and the Budget Advocacy Network's budget tracker (2012)

${ }^{8}$ See http://vhfc.org/home 
stemming from complex socio-political factors. In this, preparedness is understood in terms of scientific capabilities, as a means of overcoming difficult social and political drivers. According to Vogel, 'In light of poor intelligence information and the unpredictability of advances in life science, this science-based approach is seen as providing a more robust and rapid mechanism for developing countermeasures against a broad range of potential BW attacks' (Vogel 2008: 230). The core post-war activities in Kenema, at least until 2013, were supported by this model of preparedness as funding flowed for research on pathogenesis and genomics for diagnostics and treatment.

In private researchers debate the Category A classification and its implications. There are doubts within the scientific community that Lassa would make an effective weapon as contact with infected bodily fluids is needed to transfer the disease reliably. Whether the prospect of weaponisation is regarded as sensationalism or a real concern, all researchers are aware of the utility the bioweapon threat has in obtaining funding. As a Tulane researcher explained:

So does scare and the paranoia keep some of these agents in the high category? Yeah probably. But is it possible that it can go beyond, yes of course it is possible, but so far nothing really has happened. But we certainly spend a lot of money on preparing [...] it keeps people employed, keeps science moving forward.

(Tulane researcher: Kenema, 2 March 2010)

On the ground in Sierra Leone, the work of keeping science moving and keeping the world 'safe' sees biosecurity grafted on to a range of agendas. In a resourced-stretched health system, biodefense concerns are largely alien but they provide an injection of otherwise scarce resources. A MOHS doctor explained:

The average Sierra Leonean won't see LF as a bioterror threat. Only in the Western world do they see it like that. They see it coming from here as a weapon [...] All the knowledge produced here could be used to help counter bioterror. But we do not see it like that.

(KGH and Lassa ward clinician 2: Kenema, 23 October 2013)

For $\mathrm{KGH}$, the research funds flowing into the Lassa laboratory provide opportunities to improve clinical practice. During development, using samples from Sierra Leonean populations, the prototype diagnostics are provided to Kenema Government Hospital for free. The research projects have created work and skill development opportunities for Sierra Leonean staff employed at KGH. Research funds have also supported the outreach and surveillance team to do community sensitisation on Lassa. This reflects a broader trend whereby the traditional roles of defence and health agencies are blurred as defence actors become involved in humanitarian and development work (Bonventre et al. 2009). In this case, research, defence and health system strengthening are brought together in an uneasy blend. The Metabiota projects in Sierra Leone fall under the auspices of 'cooperative threat reduction' or 'white coat diplomacy', funded by the Departments of Defense and State (Metabiota staff: Skype, 3 October 2013). Yet when grants are primarily for research, the diplomatic spillovers, be it clinical support or training, are not always clear cut. In particular, the provisions within research projects for longer term capacity development and training of national staff seem to jar with local expectations. Tulane and Metabiota promoted their own efforts, at times vis-à-vis each other, while MOHS officials and project staff suggest more could be done. Comparisons were drawn between the unequal number of Masters and PhD students who come to work on projects and collect data in $\mathrm{KGH}$ compared to the number of Sierra Leonean project staff who are supported to receive formal qualifications or training abroad. Diplomacy is also undermined by inter-organisational disputes with national staff having to mediate between Metabiota and Tulane conflicts. One clinician 
commented, 'Now we have the troubles of one organisation to another, it is giving me a headache' (KGH and Lassa ward clinician 1: Kenema, 23 October 2013).

Further complicating the research-defence-health system strengthening nexus are the financial incentives driving innovation, which for tropical diseases in poor countries, have traditionally been minimal, suffering from market failure. One outcome of the 'securitisation' of Lassa fever is that it is hoped the countermeasures will become commercial products and researchers have specific markets in mind. Post 9/11 the US Government formed the US Africa Command (AFRICOM) and planned to station some, or all, of this new military outfit in Liberia, creating a potential market for Lassa 'products':

So in a Lassa endemic area, what is that going to mean? [...] Lassa fever is obviously going to be on the list of things to test, so having a quick rapid assay to test for Lassa fever, and a confirmatory assay, and the ability to treat this person is going to be important. So the United States Government and NATO allies are going to be customers for these diagnostics at some point.

(Tulane researcher: Kenema, 2 March 2010)

According to a Metabiota researcher, early product development is the traditional role of military research especially in the realm of emerging diseases (Metabiota staff: Skype, 3 October 2013) and the results, such as vaccines, eventually make their way to civilian populations. For the diagnostic development led by Tulane, wealthier Nigeria has been suggested as a plausible market. However, for Sierra Leonean populations this trickle down model is uncertain and the provision of diagnostics is currently tied to the availability of research programmes. Crucially, there is no formal agreement between the MOHS and Tulane and their partners about how the diagnostics will be supplied once research and development is completed (Tulane researcher: Segbwema, 21 October 2013). Significantly, much of this research is done in partnership with private companies who are profit driven:

For a Western organisation, such as Corgenix, a publically traded company, they'll have investors to answer to so they can't just say, 'hey, we're doing wonderful things in Africa but unfortunately we burnt 60 cents, and we make 10, so we lose $50^{\prime}$. You know investors are really not that keen on that.

(Tulane researcher: Kenema, 2 March 2010)

Even when buoyed by biodefense funds during product development stages, it is common for small biotech companies to struggle to bring their products to market.

While Lassa can no longer truly be called a neglected disease, scrutiny of the distribution and direction of disease control efforts in the Sierra Leonean context is needed. By 2010 some researchers were beginning to question the diversity of research in Sierra Leone:

The problem is a lot of money is being devoted to Lassa in terms of therapeutics, vaccines, diagnostics. But there is no money whatsoever for prevention, education, for health promotion. For understanding the epidemiology and transmission dynamics of Lassa, nothing.

(Tulane researcher: Kenema, 11 April 2010)

This observation invites questions about the biodefense funding model and its limitations. A common critique is that biodefense funds have absorbed money which would otherwise have been used for a wider array of disease control activities. There is some evidence to back this view. One researcher reported 
having two grants turned down by a major philanthropic organisation, without review, on account of their policy not to fund Category A pathogens. Reflecting on this they noted that Lassa's dual framing as a biodefense threat and a public health issue, 'paradoxically leads to it sometimes being overlooked by funding agencies on both sides'. That is, 'public health organisations and funders believe it is already covered under defence support, and defence agencies are not supporting the public health efforts' (Harvard University researcher: Skype, 4 October 2013). However, given that Lassa fever suffered from serious resource constraints long before the arrival of biodefense money, the relative investment in public health and prevention vis-à-vis medical countermeasures cannot be blamed simply on defence resource capture. The following section examines a parallel policy process which suggests it is better understood in the context of long-term constraints of the Sierra Leonean health system and the political economies of health policy, funding and evidence these have produced. 


\section{Becoming a national public health problem: from unknown to known}

While on the international stage Lassa fever is an emerging disease and potential bioweapon, in Sierra Leone it is an endemic disease largely associated with the East of the Country. Compared to malaria or typhoid which are common throughout the country, Lassa fever, it is said, is not a national disease. It occupies a unique place in the national mythology but, because it is conceptualised as geographically limited, it is off many people's radars. Professionals residing in Freetown spoke of Lassa fever as located in, 'that little corner of Sierra Leone' and, 'so far off' (SLIEPA staff: Freetown, 30 February 2012). Parts of the country are designated as being the Lassa belt, understood to run across the 'Kenema-Kailahun axis' (Senior MOHS staff: Disease Prevention and Control Directorate, Freetown, 28 April 2011) or, the 'axis of Kenema and Segbwema' (Senior EPA staff: Freetown, 5 February 2013).

Although money has gone into laboratory research, it has been shadowed by evidence of startling underfunding in the wider health system. For example, there was no thermometer on the Lassa ward for significant periods of the fieldwork which informs this paper, despite the fact that temperature readings are a key part of the case identification protocol. Nurses also described having to reuse needles on patients (not between patients but on the same patient over the course of their treatment). This implies needles were being recapped, putting nurses at further risk of infection. In one hospital in the Lassa belt the medical superintendent laughed when the Lassa outreach team told a room full of nurses there that they should always wear gloves to protect themselves. He interrupted them to say there were no gloves and only God would protect them. Health workers at peripheral health units (PHUs), were receptive to the outreach team's visits to train them about diagnosing and referring Lassa to KGH but would then point out they had no gloves or equipment to take samples from suspect cases.

Ebola found fertile ground in this chronic underfunding. It reasonable to expect that concern about infection control and public health for VHFs will now be higher. However, before Ebola, Lassa fever was unlikely to be top of the policy agenda in Sierra Leone. The country has faced ten years of civil war in recent memory and is consistently ranked near the bottom of the Human Development Index. In 2009, at the start of this research, it was ranked 180 out of 182 in the Human Development Index (UNDP 2009), having moved from the bottom in 2007 (UNDP 2007). It also has some of the highest rates of maternal and child mortality in the world. In this context, Lassa fever is simply one problem on a long list of pressing concerns. Priorities are constructed in terms of prevalence, not just in absolute numbers but also in spread. A senior MOHS official emphasised that as long as the virus was considered to be geographically limited, resources would be limited, 'I'll be very frank with you, [resources are] not forthcoming because [Lassa] is not being perceived by all as a nationwide threat, yet' (Senior MOHS staff: Disease Prevention and Control Directorate, 28 April 2011).

There are moments, such as the death of Dr Conteh, when attention is drawn to the plight of Lassa in Sierra Leone but these focusing events tend not to last long. In a country with multiple health and development problems high level policy interest has been episodic. After 2004 the MRU-LFN was formed and there was supposed to be regular regional meetings of it. However, it was seven years before the next regional meeting, held in 2011, and this came about largely because of a spate of infections in the North of Sierra Leone which provoked concern because they were not in the traditional Eastern zone. For a few months Lassa fever was higher on the policy agenda. There were expatriate deaths (a South African 
engineer working for a biofuels company) and it seemed to have spread out of the Lassa belt. During fieldwork in 2011 a common phrase, from surveillance officers, MOHS staff and the general public, was that it was 'everywhere but Freetown'. However, by 2012 a nationwide cholera outbreak had become the pressing concern. WHO country office staff reported that little had been done since the second regional meeting and that people and funds had once again moved on (WHO staff: Freetown, 6 February 2013).

Despite shifting priorities, the events of 2011 created a new discourse about Lassa fever, which argues that it is a nationwide problem and which needs nationwide resources and attention. An MOHS official described what this would look like:

A new approach would be for us to just take the country as it being endemic. Not only do you have the hyper-endemic areas but you really have it all over the country. And as such each and every health worker should be trained to look out and diagnose and pick out cases of it. Now more than ever the nursing barriers should be in place at all times. It also calls on all health institutions to provide the personal protection equipment for nurses, for health workers. It goes a long way in terms of the entire system [...] it means community sensitisation in previously non-endemic areas should be on-going and not a one off issue. It is a disease that does not forgive you if you make mistakes.

(Senior MOHS staff, Disease Prevention and Control Directorate: Freetown, 28 April 2011)

The vision articulated here is a bolstered nationwide public health approach the like of which has so far not been attempted in Sierra Leone. Prior to this, the Sierra Leonean approach to Lassa fever could be described as policy-less. The re-framing of Lassa fever, as a nationwide threat, hinged on the virus's detection in new areas. The role of technological change in shifting the politics of this emerging disease is pivotal. New diagnostics have improved clinical care and surveillance which in turn have provided the evidence needed to make new policy claims. Previously, conventional wisdom located Lassa only in the East. Meanwhile, scientists emphasised the patchy evidence base. In their assessment, the lack of good quality diagnostics and the absence of extensive prevalence studies contributed to a knowledge vacuum. Statements about Lassa have been couched in terms of great uncertainty and many of the established facts are dismissed as 'dogma' by Tulane researchers. One US researcher summarised the situation like this, 'Seriously, everything about Lassa, I think, needs to be re-examined. Everything published before 2000 [...]. There is a big gap, at least in field research on Lassa' (Tulane researcher: Kenema, 11 April 2010). The technology and knowledge deficit was one of the reasons that the diagnostics were focused on originally, as another Tulane researcher explained:

I was really impressed that the only way we were going to be able to get any sort of handle on things was to not jump right into community education or prevention measures because all those things require you to have some base line data, you know, what are you preventing, are you using your resources wisely, if you say we're going to go out and do community education or prevention, where are you going to do it? How much Lassa is there really in one particular region, or one village? The only way you could know, answer any of those questions was to have reliable diagnostics. And then start to collect information that was objective and could be verified and say here is where our Lassa cases come from, here is what is real and here is what is not real.

(Tulane researcher: Kenema, 27 March 2010)

This interviewee added that with the diagnostics as building blocks it would be possible to obtain 'valid public health information' in order to 'direct your resources appropriately'. Scientific evidence is felt to be 
a prerequisite for action and policy. In a funding and policy landscape which still tends towards vertical interventions, and which is under pressure to be evidence based and accountable, laboratory supported facts and figures are powerful. As it is increasingly clear that Lassa fever is not limited to the East of the country, and now Ebola has also been found regionally, the idea of neatly focusing resources on areas at risk of particular diseases is more clearly problematic. An alternative would be developing broader institutional capacity to deal with Lassa among a range of communicable disease challenges, at national, district, and community levels, and including public, private and informal components of the health system.

The institutional resistance of international public health to acting in contexts of uncertainty contrasts with the knowledge processes propelling biodefense interventions. As argued by Vogel (2008) biodefense is built on preparing in the face of ambiguous potential threats. As a policy framework it deals in the unknown and thrives on uncertainty. Public health prevention and disease control, however, relies on statistics for raisings funds and awareness, for policy making, and critically, for monitoring impact. This is emphasised by a senior MOHS official:

So resources for Lassa sensitisation, Lassa training, are not forthcoming. Last year we approached WHO and we have thrown this to some NGOs working in some of these districts to pick up this as an issue. But you know before ever things become a priority you need to see data, case notes, and its coming and by all means the focus on Lassa will soon take place but it won't take place immediately because there are other priority diseases which have attention and continue to.

(Senior MOHS official, Disease Prevention and Control Directorate: Freetown, 28 April 2010)

He added later that 'it [Lassa] is an unknown'. Hard data is required before, and in order for, Lassa to compete with other diseases for attention and resources. There were disagreements about the direction of the LFN-MRU at its outset and some stakeholders wanted to focus on community based prevention or improving the ward (Tulane researcher: Kenema 27 March 2010). However, the focus on diagnostics and surveillance finally won. Lassa needed to make the transition from an unknown to a known disease. The transition pathway was conceptualised as flowing from scientific knowledge. Laboratory knowledge was prioritised as diagnostics were required as the first step in making Lassa manageable. The differing attitudes towards uncertainty between biodefense and public health helps to explain the dominance of biodefense funded projects for Lassa fever up till now.

As the knowledge base for Lassa fever matures and is renegotiated, possibly, into a 'national disease' some of the more ingrained perceptions about the disease are also being challenged. Not only does the virus's geographic spread look significantly different but so too does its 'typical' symptoms. New diagnostics are finding evidence of milder infections which is reshaping the diagnostic profile of the disease (Branco et al. 2011). Integrating a more nuanced understanding of what the disease looks like in a patient is an incredibly complex task and it has implications for the health system as a whole. The scary 'bleeding disease' card which has been useful for attracting resources for Lassa previously may be less helpful in meeting this objective. Sensationalisation about Lassa, and indeed Ebola, can prevent them being dealt with in the calm and measured way which is so critical. It was common to hear nurses talk about how they feared and tried to avoid nursing jobs in the Lassa belt. Doctors at KGH described cases being declined admission to other hospitals if there was the slightest suspicion that they may have Lassa. Overcoming the often inaccurate images of bleeding orifices and rapid death is a challenge for dealing with the disease as a complex public health issue. It runs counter to helping the public and health workers understand the varied way the disease actually presents, and extending treatment, infection control and suspicion beyond 
Kenema and the East, now all the more important post-Ebola. Recent trends in health system strengthening have made attempts to embrace complexity and uncertainty, for example by applying the concepts of complex adaptive systems (Paina and Peters 2012). Such lenses may be helpful for building on the tools provided with biodefense research and integrating new understandings of Lassa and the viral makeup of the region into the health system post-Ebola. 


\section{The scope for One Health}

One Health argues for an integrated approach to human, animal and ecosystem health on account of their interdependencies (Zinsstag et al. 2011). Hinchliffe (2014) identifies broad and narrow versions of One Health. In the former the focus is on tracking and preventing the transmission of pathogens. Though this can bring together agricultural, veterinary and human health institutions it operates a one dimensional understanding of shared risks which focuses on surveillance and containment. The latter draws attention to the complex socio-economic configurations of disease and health, viewed as the product of heterogeneous practices in specific locations. It picks apart assumptions about 'one worldism' in One Health and replaces them with the notion of many contingent worlds. A broad version of One Health incorporates not just multiple disciplines but also forms of knowledge and evidence, and socio-cultural understandings of people-animal-environment interactions. This section assesses the extent to which these interdependencies have been considered for Lassa fever and identifies some of the politics shaping this domain of policy making.

As well as the clinical and diagnostic work going on at the Lassa ward and laboratory at KGH there is also a core group of staff who carry out surveillance, community outreach and rodent-trapping, supported by the research funds. Some of these frontline workers have worked on Lassa for decades. They embody the deep history of Lassa fever research in Sierra Leone and have unmatched expertise of the disease in context. Working in close contact with the laboratory and ward at $\mathrm{KGH}$, and with visiting scientists, they provide a vital bridge between the community and hospital settings and are the backbone of clinical, prevention and research activities. When a positive case is confirmed it triggers both human contact tracing and rodent trapping. Community outreach benefits from their deep knowledge of the local terrain and kinds of connections between human and rodent life in it. In many ways the integration of spatial (villages, bush, hospitals, labs) and knowledge domains (bioscience, human health, rodent ecology) achieved at KGH in, 'that little corner of Sierra Leone', is what One Health aspires to.

While activities at KGH may be joined up, the scope of research and disease control activities are limited when viewed from a broad One Health perspective. After a flurry of early research, much by CDC, field studies on Lassa have been scarce. The previous sections have highlighted how the thrust of recent research on Lassa fever has been focused on human health, particularly the development of diagnostics, treatment and vaccines and the incentives driving that. In contrast, little is known about disease distribution and vulnerability in West Africa. The lack of clarity about the meaning of apparently expanded disease territory (Gire et al. 2012) highlights this. Variation in estimated annual infections is huge, ranging from 100,000-300,000 cases a year with as many as 5,000 deaths (McCormick et al. 1987b), to up to three million new infections a year with 67,000 deaths (Richmond and Baglole 2003). Significant questions remain concerning the apparent disparity between the distribution of Mastomys habitat and recorded incidence of disease (Moses et al. 2012). Even less is known about factors which might influence distribution patterns. Fichet-Calvet and Rogers (2009) investigated climatological influence on the distribution of Lassa by compling data on human infections from 1952-2007 and using it to draw predictive maps. Their results suggest that heavy rainfall and temperature impacted on Lassa fever distribution, with rainfall exerting most influence according to their data. However their models did not include rodent data and it has been suggested that the predictive maps may be best for predicting where humans get diagnosed rather than ecological niches of the virus (Moses et al. 2012). The availability of diagnostics and socio-economic factors affecting people's access to them cannot be separated from the uncertainties about ecology, climate and prevalence. A case in point is understanding why more cases of Lassa fever are 
reported in the dry season. Seasonal fluctuations may be due to the stability of the virus in different temperatures and humidity linked to rainfall, and ebbs and flows in infected rodent populations (FichetCalvet et al. 2007; Fichet-Calvet and Rogers 2009). They may also be due to the condition of roads during the rains, agricultural duties and lack of funds in conjunction with harvesting patterns (Bausch et al. 2013) but these ideas remain hypothesises. Moreover they relate to accessing care, not exposure. These gaps underscore the need for One Health's integration of human, animal and ecosystem health.

Understandings of social, economic, technical, and environmental drivers of Lassa prevalence in human or rodent populations are further constrained. The impact of the civil war and development trends towards large scale agriculture or mining activity are unexplored. However in Sierra Leone well-known hotspots for Lassa overlap with long time mining areas, and new cases in the North were detected in areas undergoing transitions to large-scale farming. There has been almost no research looking at macro socio-economic or ecological trends which may drive exposure, either major changes in land use or seasonal agricultural practices. Patterns of transmission linked to farming practices and livelihood strategies, old and new, and across gender roles are not known.

The result is that disease control and prevention strategies based on an understanding of everyday practice and differential and changing vulnerability to Lassa are not possible. Instead the prevention work carried out by the outreach team is based on CDC work from before the war. It can be summarised as, don't eat rats, keep your environment clean and go to the doctor if you have a fever. The effectiveness of such messages is doubtful:

When we go and we do community sensitisation, or if you go and you read the WHO background page on Lassa fever, you know they talk about 'good community hygiene' but what that is precisely, to prevent Mastomys, specifically, no one really knows. No one has gone through and said, does trash, eliminating trash piles near your house actually reduce Mastomys populations? Or rodent populations in general? [...] All the information campaigns, all the community education, all the recommendations that the outreach team gives now, it's just common sense stuff: what do you do to reduce rodents in your house? 'Don't have food in your house', which is impossible for Sierra Leoneans to pull off. I mean, most people all over the world keep food in their house.

(Tulane researcher: Kenema, 11 April 2010)

Of more importance, this researcher suggested, is the fact that Mastomys are burrowing animals. Dirt floors are common where cement cannot be afforded, thus poverty may be a better indicator of risk. Existing prevention messages advocating hygiene overlook such socio-economic conditions. They may also be missing gender-differentiated exposures which occur seasonally during the agricultural cycle, for example the work which women do in vegetable gardens where soil mounds provide hospitable burrowing opportunities for Mastomys natalensis.

The research portfolio at KGH has begun to diversify and include more field studies. Metabiota's project to model the influence of climate on disease incidence includes both rodent and human data and so will be strengthen the evidence base on climate and distribution. The genetic work done by Harvard University and their collaborators is bringing a longer term perspective to Lassa fever. In 2011 the Dynamic Drivers of Disease Consortium, which this case study is a part of, began multi-method and participatory research into the ecological, epidemiological and environmental drivers of Lassa virus transmission, focusing especially on local livelihood and ecosystem service processes, including land-use patterns, climate, biodiversity, geography and lifestyle patterns (ESPA 2014). In 2012 a Tulane researcher obtained UK 
Department for International Development (DFID) funding to work with GOAL, an Irish NGO, to test rodent control methods in an effort to update disease prevention messages and techniques. Collectively these efforts are broadening out the research base and will enrich understandings of the disease in its social and ecological context.

Research and control methods pursued through the IDSR, the MRU-LFM and the VHFC have focused on improving surveillance and treatment by improving how cases are diagnosed, tracked and treated. As such they are based on a 'contamination' model of disease control which focuses on pathogen transmission. Medical historian Charles Rosenberg contrasts this with a 'configuration' model of disease which is concerned with the interacting social, medical and economic factors in context (Rosenberg 1992). New research is beginning to establish granular, locational and historically contextualised understandings of Lassa which have been missing. With promising research on the horizon the politics of policy processes become especially critical. It remains to be seen how new knowledge about how Lassa is configured in villages, fields, gardens, and by whom and in relation to which livelihood activities can be put into practice.

Dominant narratives about Lassa fever contain some troubling patterns. The persistence of the idea that Lassa fever is located only in that 'little corner of Sierra Leone' sees Lassa fever located in rural backwaters of little concern to urbanised areas such as Freetown where most business, government and NGOs are based. This also relegates Lassa fever to an area associated with the civil war which began in the East. ${ }^{9}$ Furthermore, Lassa fever's infection route is easily stigmatised and it converges with the perception that rural people living 'up country' are less civilised. The reason Lassa fever is only in the East, it is said, is because that is where people are driven by ignorance and tradition making them behave in risky ways. The consumption of rodents as a source of protein receives considerable scorn, 'there is no better way of getting the disease than by eating its carrier', said one Freetown professional. He went on to say that hygiene was also important and that the area where Lassa is most prevalent is where hygiene is poor and rats are eaten (Octea Mining staff: Freetown, 31 January 2013). Basic standards of hygiene were mentioned across interviews, and poor hygiene was equated with a lack of education (Senior EPA official: Freetown, 5 February 2013). Many of these discourses are repeated with Ebola: the initial laying of blame on bush meat consumption; and the assumed superstition of rural people. Even the virus's route into the country followed the same pattern, reinforcing the view for some that everything bad that happens to Sierra Leone comes from Kenema.

These stigmatising perspectives on Lassa, which work to attribute responsibility to individual's behaviour as opposed to socio-economic conditions or long-term ecological change, are troubling in a context where ideas of disease and development can so easily become entwined. Post-war Sierra Leone has sought to move up from the bottom of the human development index and discard its blood diamond label by achieving growth. The Sierra Leone Investment and Export Promotion Agency (SLIEPA) was formed in 2007 and seeks to promote investment opportunities in the country, particularly from foreign investors. It has focused on agriculture, identifying sugar cane and oil palm as priority investment areas (SLIEPA representative: Freetown, 30 February 2012). Commercialisation and diversification of agriculture by the private sector is proposed as a key means of achieving change (GOSL 2005). Large scale land-deals, farming and mining are the order of the day.

\footnotetext{
${ }^{9}$ The border with Liberia and Eastern Sierra Leone saw the brunt of fighting in the 10 year civil war.
} 
Changes to the landscape may well influence rodent populations and disease ecology but debate about the implications of these environmental and economic changes is absent. Indeed institutional reluctance to consider the possibilities was evident from key stakeholders. During interviews, farming and mining industry actors did not see connections between their work and zoonotic diseases such as Lassa fever. Both London Mining ${ }^{10}$ and Octea Mining ${ }^{11}$ staff interpreted questions about the potential health implications of their operations as concerning staff getting sick. Otherwise they saw their activities as unrelated and argued, for example, that Lassa fever was simply about people's culture and behaviour. It is 'society generic not mining operation specific (Octea Mining employee: Freetown, 31 January 13). The mining companies, and the EPA who oversee their licences, view the impact of mining activities through the limited lens of the Environmental, Social, and Health Impact Assessments (ESHIA). This covered only those issues which were described as 'mining related health issues' (Octea Mining employee: Freetown, 31 January 2013) like noise, dust and human resettlement. Health outcomes are framed as immediately observable with direct causal links. Messier, longer term and indirect outcomes are not contemplated and are not included in impact assessments. Interviewees discounted them by separating mining activities off from wider social or ecological processes. An equilibrium view of the world is created where impacts can simply be mitigated or compensated. The direct links between Lassa fever, rodent consumption and poor hygiene are preserved as the primary drivers of infection and consideration of long-term and non-linear impacts of changing land use is avoided.

Hinchliffe's (2014) broader, deeper conceptualisation of One Health emphasises that there is not one world, but different worlds and different perspectives. Putting this into practice would mean integrating plural forms of knowledge, especially the views and experiences of local people into research and disease control. If outbreak narratives dominate on the global stage, and episodic, and at times stigmatising views of Lassa fever are held in Freetown, very little attention has been paid to the perspectives of those who are most affected by Lassa fever. Ethnographic research in Eastern Sierra Leone uncovered some rather different understandings of the disease and reasons for susceptibility to it (Wilkinson 2013). In village settings Lassa fever was not emerging but was part of existing disease landscapes where categorisations of sicknesses correspond, less to causative agents, and more to the available treatment options and social relations of sickness. In Mende areas Lassa fever is known, along with other, similar fever producing illnesses as a 'big fever' or a 'hospital sick', as opposed to a 'small fever' or an 'ordinary sick' which can be managed at home. The name Lassa has only recently been introduced by doctors, and 'white people'. The message to go to a government clinic if you have fever is deceptively simple, as is the classification of fever types. Ordinary sicks become hospital sicks unpredictably, and these sickness categorisations intersect with economic, spatial and social factors. A hospital sick can only become a hospital sick in practice if a patient has family, friends and money to assist their health seeking journey, including paying for consultation, paying for transport or carrying them by hammock for hours on bush paths to a health facility. Lassa fever treatment and ambulance transportation is free but until that label is applied in a health facility the barriers are the same as they are for other diseases. As a more attractive and accessible alternative many people use informal and private providers practicing biomedicine and/or non-allopathic methods.

Though rats are widely known to be the carriers of Lassa fever people raise questions about individual cases. The role of rodent consumption, the discouragement of which is a key part of Lassa fever health

\footnotetext{
${ }^{10}$ London Mining mined and exported Iron Ore from Tonkolili district. It went bankrupt in 2014.

${ }^{11}$ Octea Mining mine diamonds in Kono district.
} 
prevention messages, is often disputed. As is characteristic of Mende social life (Ferme 2001) much about disease causation is ambiguous and public health information is not considered to be the end of the story in many cases. Fitting into existing ideas about misfortune and witchcraft, the deaths of pregnant women from Lassa (a group who are particularly vulnerable to the disease) are often said to have broken important social, ecological or ritual rules and therefore to have brought it upon themselves. Questions about the surrounding environment, for example the quality of water sources, are also common. As such, the experiences of local people mean explanations for vulnerability to Lassa are grounded as much in social, economic and ecological dynamics as they are in biomedical mechanisms. This suggests that prevention methods and communication relying solely on giving biomedical information but which overlook the realities and perspectives of people at risk of the disease, will have limited effect. 


\section{Conclusion}

The question of whether Lassa's expanded territory is 'emerging disease or diagnosis' (Gire et al. 2012) hints at the socio-technical processes underpinning Lassa fever's discovery and recognition. It is not simply a new virus disease of man coming out of Africa. The co-evolution of science, technology and policy has constructed different versions of Lassa fever over time. This paper has identified policy and knowledge processes which have underpinned the transition from a neglected disease to an exceptional high priority pathogen, through to a national public health threat. This progression has been shaped by shifting assemblages of people, tools, economies, framings, styles of reasoning, interests and values.

The scale of the Ebola crisis necessitates reflection on preparedness and biosecurity. Strong critiques of have been made of how the tropes of pandemic preparedness, bioterrorism and emerging diseases have dealt in imaginary threats (Caduff 2014; Vogel 2008) and produced imaginary interventions (Lachenal 2014). In Sierra Leone the threat of bioweapons may have been largely imaginary but the problem of Lassa was real and tangible, and biodefense money has contributed to significant developments in diagnostics. The nascent articulation of Lassa fever as national public health problem establishes a version of preparedness based on health systems which is broader in scope than that of biodefense. So far the national public health framing of Lassa has involved talk of surveillance, training and PPE for health workers. Missing from the discussion however has been the vector itself, Mastomys natalensis, and its relationship with social, economic and environmental processes at community, regional and national levels. The view of rodents as pests who are not economically important in the way that livestock is, for example, may have influenced this.

Distinct policy assemblages have reconfigured Lassa over time. By engaging differently with uncertainty Lassa has shifted from an unknown entity to an (increasingly) known and visible one. Biodefense funding and science has been pivotal in establishing a valid evidence base for Lassa fever. However the uncertainty narratives that have been told about Lassa fever, which emphasise a knowledge and technology deficit, overlook important alternative sources of knowledge which should now be integrated. It is unclear how the new certainties of Lassa fever will play out. Leach and Scoones have argued that all data, disciplines and models are selective, efforts to integrate them should seek to explore their positioned nature and include deliberation around framing assumptions, narratives, cultural understandings and values (Leach and Scoones 2013). Both biosecurity and public health approaches prioritise laboratory knowledge (as the basis of counter threats or of evidence based policy) and have come to focus on reducing transmission. Unpicking the configuration of the disease in field contexts, in particular the interaction with gender, socioeconomic status and forms of 'development', has happened less. As Lassa proves itself to be a more common and complex disease than first assumed, plural forms of evidence can contribute to contextually appropriate, diverse and more resilient response pathways.

Recognising and integrating the knowledge of a broad range of actors, especially frontline workers, field staff, social and political scientists, and urban and rural populations is essential. The Lassa ward suffered appalling loses in the Ebola epidemic, as did the general health sector in Sierra Leone, but those remaining have gone on to play pivotal roles in turning Kenema's fate around and now have a deepened knowledge of viral haemorrhagic fevers in the local context. Local communities have also learned rapidly and developed effective protective community based responses (Richards et al. 2015; Abramowitz et al. 2014). Ebola has demonstrated how fragile local expertise is if not nurtured and supported. 
A broad One Health approach, concerned with interdependencies but also with politics, social justice and context, draws attention to plural forms of evidence and diverse values. Applying such a lens is urgent as Lassa emerges as a national disease, as the MRU-LFN ends its first decade, and as the Mano River recovers from Ebola. One Health, and Global Health more generally, speak a language of shared risks and vulnerability. Yet the contrast between contamination and configuration approaches to disease, and evidence of dramatically different perspectives on Lassa and on health, complicates the idea of shared vulnerabilities. It points, not just to the importance of socio-economic conditions but, crucially, also to the way such conditions can be systematically overlooked by dominant policy perspectives. The scope for an effective One Health approach, which attends to disease as produced in and by complex interactions, will be influenced by the extent to which inequality, structural violence and social justice are considered as drivers of human and animal health. Questions must be asked about whether the pathways of development currently being pursued, heavily reliant on foreign direct investment, mining and land grabs, drive vulnerability and exclusion or reduce it. The increasing number of non-traditional actors involved in global health, including defence agencies, biotech and for profit firms, creates the potential for divergent interests. Therefore it is all the more important to pay attention to the effects of power and politics on science and policy and to ask whose world is being defined, by whom and how. This can be laborious but the Ebola epidemic has highlighted the problems caused by weak health systems which local populations do not trust or feel connected (Wilkinson and Leach 2015). A new approach to managing human, animal and ecosystem health which draws in a range of expertise, which recognises and addresses socio-economic drivers and differential vulnerabilities, and which engages with the priorities of local populations should be a priority for post-Ebola Mano River. 


\section{Bibliography}

Abramowitz, S. A., Mclean, K., Mckune, S. L., Bardosh, K. L., Fallah, M., Monger, J., Tehoungue, K. and Omidian, P. A. (2014) Community-Centered Responses to Ebola in Urban Liberia: The View from Below, Research Paper, http://bit.ly/1N4YHbw

Akam, S. (2011) U.S. anti-terror outpost tackles rat-borne virus, Reuters US, http://reut.rs/1GCh960 (20 March 2012)

Bausch, D. G., Moses, L. M., Goba, A., Grant, D. and Khan, H. (2013) ‘Lassa Virus Hemorrhagic Fever’ in S. K. Singh and D. Ruzek (eds) Viral Hemorrhagic Fevers, Abingdon: Taylor and Francis

Bausch, D. G., Sesay, S. S. S. and Oshin, B. (2004) 'On the front lines of Lassa fever', Emerging Infectious Diseases 10: 1889

Birmingham, K. and Kenyon, G. (2001) 'Lassa fever is unheralded problem in West Africa', Nature Medicine 7: 878-878

Bonventre, E. V., Hicks, K. H. and Okutani, S. M. (2009) 'U.S. National Security and Global Health: an analysis of Global Health Engagement by the U.S. Department of Defense', a report of the CSIS Global Health Policy Center - Working Draft, Washington DC: Centre for Strategic and International Studies (CSIS)

Borio, L., Inglesby, T., Peters, C., Schmaljohn, A. L., Hughes, J. M., Jahrling, P. B., Ksiazek, T., Johnson, K. M., Meyerhoff, A. and O'Toole, T. (2002) 'Hemorrhagic fever viruses as biological weapons', JAMA: the journal of the American Medical Association 287: 2391-2405

Branco, L., Grove, J., Boisen, M., Shaffer, J., Goba, A., Fullah, M., Momoh, M., Grant, D. and Garry, R. (2011) 'Emerging trends in Lassa fever: redefining the role of immunoglobulin $\mathrm{M}$ and inflammation in diagnosing acute infection', Virology Journal 8: 478

Caduff, C. (2014) 'Pandemic Prophecy, or How to Have Faith in Reason', Current Anthropology 55: 296315

Calain, P. (2007) 'Exploring the international arena of global public health surveillance', Health Policy and Planning 22: 2-12

CDC (2012) Emergency Preparedness and Response - Bioterrorism Agents/Diseases Atlanta GA: Centers for Disease Control and Prevention, http://www.bt.cdc.gov/agent/agentlist-category.asp (15 December 2012)

Collier, S. J. and Ong, A. (2005) 'Global Assemblages, Anthropological Problems' in A. Ong and S. J. Collier (eds) Global Assemblages: technology, politics and ethics as anthropological problems, Oxford: Blackwell

Donaldson, R. (2009) The Lassa Ward: one man's fight against one of the world's deadliest diseases, London: Transworld Publishers 
Dry, S. (2008) Epidemics for all? Governing health in a global age, STEPS Working Paper 9, Brighton: STEPS Centre

Elbe, S. (2010) 'Haggling over viruses: the downside risks of securitizing infectious disease', Health Policy and Planning 25: 476-485

ESPA (2014) Designing research for development impact. Evidence Note, Edinburgh: Ecosystem Services for Poverty Alleviation

Farmer, P. (1999) Infections and inequalities: the modern plagues, Oakland CA: University of California Press

Farmer, P., Bourgois, P., Scheperhughes, N., Fassin, D., Green, L., Heggenhougen, H., Kirmayer, L. and Wacquant, L. (2004) 'An Anthropology of Structural Violence 1', Current Anthropology 45: 305-325

Ferme, M. C. (2001) The Underneath of Things: violence, history, and the everyday in Sierra Leone, Oakland CA: University of California Press

Fichet-Calvet, E. and Rogers, D. J. (2009) 'Risk maps of Lassa fever in West Africa', PLoS Neglected Tropical Diseases 3, e388. doi: 10.1371/journal.pntd.0000388

Fichet-Calvet, E., Lecompte, E., Koivogui, L., Soropogui, B., Doré, A., Kourouma, F., Sylla, O., Daffis, S., Koulémou, K., Ter Meulen, J. (2007) 'Fluctuation of abundance and Lassa virus prevalence in Mastomys natalensis in Guinea, West Africa', Vector Borne Zoonotic Diseases 7.2: 119-28

Frame, J. D., Baldwin Jr, J. M., Gocke, D. J. and Troup, J. M. (1970) 'Lassa fever, a new virus disease of man from West Africa. I. Clinical description and pathological findings', American Journal of Tropical Medicine and Hygiene 19: 670-676

Franco, C. (2009) 'Billions for biodefense: federal agency biodefense funding, FY2009-FY2010', Biosecurity and Bioterrorism: Biodefense Strategy, Practice, and Science 7: 291-309

Fuller, J. G. (1974) Fever! The Hunt for a New Killer Virus, New York NY: Reader's Digest Press

Garrett, L. (1994) The coming plague: newly emerging diseases in a world out of balance, New York NY, Penguin

Garry, R. (2004) 'Preclinical development of recombinant antigen Lassa fever diagnostics - Technical Proposal', Bethesda MD: National Institutes of Health

Gire, S. K., Stremlau, M., Andersen, K. G., Schaffner, S. F., Bjornson, Z., Rubins, K., Hensley, L., Mccormick, J. B., Lander, E. S. and Garry, R. F. (2012) 'Emerging Disease or Diagnosis?', Science 338: 750-752

GOSL (2005) 'Sierra Leone Poverty Reduction Strategy Paper', Freetown: Government of Sierra Leone

Gostin, L. O. and Friedman, E. A. (2014) 'Ebola: a crisis in global health leadership', The Lancet 384: 13231325 
Gronvall, G. K., Fitzgerald, J., Chamberlain, A., Inglesby, T. V. and O'Toole, T. (2007) 'High-containment biodefense research laboratories: meeting report and center recommendations', Biosecurity and Bioterrorism 5: 75-85

Hinchliffe, S. (2014) 'More than one world, more than one health: Re-configuring interspecies health', Social Science and Medicine Soc Sci Med. doi: 10.1016/i.socscimed.2014.07.007

Homeland Security Newswire (2010) Tulane University, Corgenix awarded $\$ 15,000,000$ to expand Lassa fever research, 10 February, http://bit.ly/1A7TIIW (23 February 2015)

Ingram, A. (2005) 'The new geopolitics of disease: between global health and global security', Geopolitics 10: $522-545$

Jasanoff, S. (2005) Designs on Nature: Science and Democracy in Europe and the United States, Princeton NJ: Princeton University Press

Keeley, J. and Scoones, I. (2003) Understanding Environmental Policy Processes, London: Earthscan

Khan, S. H., Goba, A., Chu, M., Roth, C., Healing, T., Marx, A., Fair, J., Guttieri, M. C., Ferro, P. and Imes, T. (2008) 'New opportunities for field research on the pathogenesis and treatment of Lassa fever', Antiviral Research 78: 103-115

Knorr Cetina, K. (1999) Epistemic cultures; how the sciences make knowledge, Cambridge MA: Harvard University Press

Lachenal, G. (2014) Ebola 2014: chronicle of a well prepared disaster, Somatosphere, http://somatosphere.net/2014/10/chronicle-of-a-well-prepared-disaster.html, (12 December 2014)

Lakoff, A. and Collier, S. J. (2013) Biosecurity interventions: global health and security in question, New York NY: Columbia University Press

Leach, M., Scoones, I. and Stirling, A. (2010a) Dynamic sustainabilities: technology, environment, social justice, London: Earthscan/James \& James

- (2010b) 'Governing epidemics in an age of complexity: Narratives, politics and pathways to sustainability', Global Environmental Change 20: 369-377

Mccormick, J. B., Fisher-Hoch, S. and Horvitz, L. A. (1999) Level 4: Virus hunters of the CDC, New York NY: Barnes and Noble

Mccormick, J. B., King, I. J., Webb, P. A., Johnson, K. M., O'Sullivan, R., Smith, E. S., Trippel, S. and Tong, T. C. (1987a) 'A case-control study of the clinical diagnosis and course of Lassa fever', Journal of Infectious Diseases 155: 445-455

Mccormick, J. B., Webb, P. A., Krebs, J. W., Johnson, K. M. and Smith, E. S. (1987b) 'A Prospective Study of the Epidemiology and Ecology of Lassa Fever', The Journal of Infectious Diseases 155: 437-444

Mccormick, J. B., King, I. J., Webb, P. A., Scribner, C. L., Craven, R. B., Johnson, K. M., Elliott, L. H. and Belmont-Williams, R. (1986) 'Lassa Fever', New England Journal of Medicine 314: 20-26 
MERLIN (2002) Continuation of Emergency Medical and Nutritional support in the Eastern and Western Regions in Sierra Leone, MERLIN-OFDA Final Report, London: MERLIN

MOHS (2008) Technical Guidelines for Integrated Disease and Surveillance and Response in Sierra Leone, Freetown: Government of Sierra Leone, Ministry of Health and Sanitation, Directorate of Disease Prevention and Control

Monath, T. P. (1975) 'Lassa fever: review of epidemiology and epizootiology', Bulletin of the World Health Organization 52: 577-592

Monath, T., Mertens, P., Patton, R., Moser, C., Baum, J., Pinneo, L., Gary, G. and Kissling, R. (1973) 'A hospital epidemic of Lassa fever in Zorzor, Liberia, March-April 1972', The American Journal of Tropical Medicine and Hygiene 22: 773-779

Monath, T. P., Newhouse, V. F., Kemp, G. E., Setzer, H. W. \& Cacciapuoti, A. (1974) 'Lassa Virus Isolation from Mastomys natalensis Rodents during an Epidemic in Sierra Leone', Science 185: 263-265

Moses, L., Kamara, A., Gorgra, A. and Koroma, B. (2012) 'Lassa Fever Case Study: Situation Analysis', Dynamic Drivers Of Disease In Africa Research Programme, Brighton: STEPS Centre

MRU-LFN (2004) 'Final Declaration of the Sub-Regional Meeting on Lassa Fever Control in the Mano River Union Countries', 13-14 September, Freetown: Governments of Sierra Leone, Guinea and Liberia

NIAID (2012) Biodefense and Emerging Infectious Diseases - NIAID Category A, B, and C Priority Pathogens, Bethesda MD: National Institute of Allergy and Infectious Diseases, http://www.niaid.nih.gov/topics/biodefenserelated/biodefense/pages/cata.aspx (15 December 2012)

Paina, L. and Peters, D. H. (2012) 'Understanding pathways for scaling up health services through the lens of complex adaptive systems', Health Policy and Planning 27: 365-373

Price, M. E., Fisher-Hoch, S. P., Craven, R. B. and McCormick, J. B. (1988) 'A prospective study of maternal and fetal outcome in acute Lassa fever infection during pregnancy', British Medical Journal 297: 584

Richards, P., Amara, J., Mokuwa, E., Mokuwa, A. \& Suluku, R. (2015) 'Village Responses to Ebola Virus Disease in Rural Central Sierra Leone', an Interim Report to the SMAC Program, Freetown: DFID Freetown/Njala University

Richmond, J. K. and Baglole, D. J. (2003) 'Lassa fever: epidemiology, clinical features, and social consequences', British Medical Journal 327: 1271-1275

Roe, E. (1994) Narrative policy analysis: Theory and practice, Durham NC: Duke University Press

Rosenberg, C. E. (1992) Explaining Epidemics, Cambridge: Cambrige University Press

Save the Children and the Budget Advocacy Network (2012) Sierra Leone Health and Sanitation Budget Tracking, Save the Children UK, www.savethechildren.org.uk/sites/default/files/docs/ Sierra Leone Health and Sanitation Budget Tracking 2012.pdf 
Schon, D. and Rein, M. (1994) Frame Reflection: Toward the Resolution of Intractable Policy Conflicts, New York NY: Basic Books

Schuler, A. (2005) 'Billions for biodefense: federal agency biodefense budgeting, FY2005-FY2006', Biosecurity and Bioterrorism: Biodefense Strategy, Practice, and Science 3: 94-101

- (2004) 'Billions for biodefense: federal agency biodefense funding, FY2001-FY2005', Biosecurity and Bioterrorism: Biodefense Strategy, Practice, and Science 2: 86-96

Sogoba, N., Feldmann, H. and Safronetz, D. (2012) 'Lassa Fever in West Africa: Evidence for an Expanded Region of Endemicity', Zoonoses and Public Health 59: 43-47

UNDP (2009) 'Human Development Report 2009. Overcoming barriers: Human mobility and development', Human Development Reports, New York NY: United Nations Development Programme

- (2007) 'Human Development Report 2007/8. Fighting climate change: human solidarity in a divided world', Human Development Reports, New York NY: United Nations Development Programme

Vogel, K. M. (2008) 'Biodefense: considering the sociotechnical dimension' in A. Lakoff and S. Collier (eds) Biosecurity interventions: global health and security in question, New York NY: Columbia University Press

Wald, P. (2008) Contagious: Cultures, Carriers, and the Outbreak Narrative, Durham NC: Duke University Press

Wallace, A. (2011) 'Broomfield's Coregenix involved in medical efforts related to Lassa fever, Ebola', Boulder Daily Camera, http://www.dailycamera.com/business/ci 17601956, (2 January 2013)

WHO (2005a) International Health Regulations (2005), Second Edition, Geneva: World Health Organization -(2005b) 'Update on Lassa Fever in West Africa', World Health Organisation, Weekly Epidemiological Record 10: 85-92

WHO and CDC (2010) Technical Guidelines for Integrated Disease Surveillance and Response in the African Region, Brazzaville/Atlanta GA: World Health Organization/Centers for Disease Control and Prevention

Wilkinson, A. (2013) The process and practice of diagnosis: innovations in diagnostics for Lassa fever in Sierra Leone, Brighton: University of Sussex

Wilkinson, A. and Leach, M. (2015) 'Briefing: Ebola-myths, realities, and structural violence', African Affairs 114: $136-148$

Zinsstag, J., Schelling, E., Waltner-Toews, D. and Tanner, M. (2011) 'From "one medicine" to "one health" and systemic approaches to health and well-being', Preventive Veterinary Medicine 101: 148-156 